\title{
Endoscopic Mucosal Resection Using Band Ligation (EBL) Will Serve Two Ends in the Treatment for Small Rectal Neuroendocrine Tumors? A Multicenter Retrospective Study
}

\author{
Il Hyun Baek ${ }^{1}$, Young Kwan Jo², Seong Hwan Kim², Kwang Ro Joo ${ }^{3}$
}

Corresponding author:

II Hyun Baek, M.D., Ph D,

Department of Gastroenterology

Eulji University Hospital

Eulji University School of Medicine

1306, Dunsan-dong, Seo-gu

Daejeon, Rep. of KOREA 35233

Telephone: +82-42-611-3063

E-mail: drandrea100@daum.net

\author{
'Department of Gastroenterology, Eulji University Hospital, Eulji University School of Medicine, \\ Daejeon, Korea \\ 2Department of Gastroenterology, Eulji General Hospital, Eulji University School of Medicine, \\ Seoul, Korea \\ ${ }^{3}$ Department of Gastroenterology, Kyung Hee University Hospital at Gangdong, \\ Kyung Hee University, Seoul, Korea
}

Received: 07.05.2018 Accepted: 12.06 .2018

Copyright () Celsius Publishing House www.sgo-iasgo.com

\section{ABSTRACT}

Background: Rectal neuroendocrine tumor (NET)s that are $<10 \mathrm{~mm}$ in diameter can be treated with local excision including endoscopic resection. Endoscopic mucosal resection (EMR) of rectal NETis often associated with involvement of the resection margin. Endoscopic submucosal dissection (ESD) has more histologically complete resection. However, ESD can lead to more serious complications and longer procedure time than EMR.Endoscopic mucosal resection using band ligation (EBL) is a new technique for eliminating the rectal NET. The aim of the this study is to evaluate the therapeutic efficacy and convenience of EBL with that of EMR or ESD for the endoscopic therapy of rectal NET.

Methods: From March 2013 to February 2018, we enrolled consecutive patients with rectal NETs less than $15 \mathrm{~mm}$ in diameter and without lymph node enlargement. The histologic complete resection rate, length of procedures, and post-procedure complications were retrospectively analyzed.

Results: Twelve NETs were excised by EBL, and 43 lesions were removed by EMR and 20 lesions were resected using ESD.The histologic complete resection rate was $66.7 \%$ in the EBL group, $74.4 \%$ in the EMR group, and $90.0 \%$ in the ESD group $(P=0.249))$. The tumor-free deep and lateral resection margins of EBL group were greater than in the EMR group $(P<0.001$ and $P=0.093$, respectively). There was no perforation in any group.Post-procedure bleeding occurred in three cases of EBL and was controlled endoscopically. Additionaly, the mean procedure time was significantly longer in ESDthan EBL $(p<0.001)$. During the follow-up period, two local recurrence and two distant metastasis were detected in the EMR group only.

Conclusions: Compared to EMR, EBL showedsimilar procedure time and complication rate, lower recurrence rate, lower lymphatic invasion, and deeper tumor free resection margin. EBL is technically easy to perform and can be safely performed in less time than ESD.EBL enables deep vertical resection margins and high complete resection ratecomparable to ESD. Considering the benefits of ease, efficiency, and short procedure time, EBL could be considered either an alternative to ESDor an optional therapy for small rectal NET.

Key words: rectal neuroendocrine tumor (NET), endoscopic mucosal resection using band ligation (EBL), endoscopic mucosal resection (EMR), endoscopic submucosal dissection (ESD) 


\section{INTRODUCTION}

Rectal neuroendocrine tumors (NET) comprise 1.1\% to $1.3 \%$ of all rectal tumors and account for $12.6 \%$ of all NETs $(1,2)$. Rectal NET is a subepithelial tumor covered with yellow-discolored mucosa. It is usually found incidentally during diagnostic endoscopy (3). Rectal NET present a wide range of behavioral aspect, from asymptomatic or benign to metastatic or disseminated. Rectal NET increases the likelihood of metastasis in proportion to tumor size. Rectal NETs that are less than $10 \mathrm{~mm}$ in diameter and confined to the subepithelial layer represent $3 \%$ of metastasis (4-6). Therefore, in small rectal NETs less than $10 \mathrm{~mm}$ in diameter, endoscopic resection is a possible therapy and improves quality of life compared to operation $(7,8)$. Rectal NETs more than $2 \mathrm{~cm}$ are usually treated surgically. However, no consensus has yet been reached for the treatment of 1 to $2 \mathrm{~cm}$ sized rectal NET.

Conventional endoscopic mucosal resection (EMR) is a popularly used and simple procedure to treat small rectal NET. However, most rectal NETs are not limited to the mucosa, but rather invade the submucosal layer. Therefore, EMR frequently produce frequent involvement of the resection margin ( $14 \%$ to $62 \%$ ). Thus, additional treatment is often required after incomplete tissue resection (9-11).

Endoscopic submucosal dissection (ESD) for rectal NET therapy has the merit of producing a higher complete resection rate than EMR because ESD contains dissection of submucosal tissue just below the lesion $(7,8,12-15)$. However, ESD is a technically complex and difficult procedure that needs skilled endoscopic techniques. Compared to EMR, ESD may cause higher risk of bleeding or perforation, higher cost, and longer procedure time.

Endoscopic mucosal resection using band ligation (EBL) is another available novel technique for the complete resection of rectal NET. EBL is technically easier than $\operatorname{ESD}(9,16,17)$. Compared to EMR, EBL can resect deeper submucosal layer $(9,17)$. There are few studies comparing EBL, EMR, and ESD as endoscopic treatments for rectal NET.

The purpose of this study is to evaluate the therapeutic efficacy and convenience of EBL in relation to EMR or ESD as endoscopic treatment of rectal NET.

\section{PATIENTS AND METHODS}

\section{Patients and lesions}

A total of 75 patients with rectal NETs who underwent endoscopic treatment from March 2013 to
February 2018 at Eulji University Hospital in Daejeon, Eulji General Hospital in Seoul, and Kyung Hee University Hospital at Gangdong in Seoul, Korea were retrospectively reviewed. No patient had symptoms of carcinoid syndrome. All rectal NETs were found accidentallyon screening endoscopy and pathologically confirmed by endoscopic biopsy prior to planned endoscopic therapy. There is still no consensus on the propertherapy for 10-19 mm sized rectal NET (18). But, the Japanese multicenter survey suggests endoscopic resection as first action for rectal NETs 11 to $15 \mathrm{~mm}$ in size that are localized to the submucosal layer (19).Therefore, if there was no depression or ulceration, we performed endoscopic resection for rectal NETs estimated to be less than $15 \mathrm{~mm}$ in diameter. The gross tumor size was measured using fully open biopsy forceps during endoscopy $(6 \mathrm{~mm}$ in width, FB-25K-1; Olympus Optical Co, Tokyo, Japan). The types of resection methods, such as EBL, EMR, and ESD, were chosen according to the preference of the endoscopist. All patients underwent computed tomography (CT) to assess the extent of pararectal lymph nodes metastasis.In CT scans on patients, all tumors did not have pararectal lymph node metastasis or distant metastasis. Endoscopic observations, procedure time, pathologic complete resection rate, complications, and follow-up findings were analyzed retrospectively.

The ethics committee of Kyung Hee University Hospital at Gangdongapproved the study design. Informed consent was gained from each patient (IRB No. KHNMC 2015-07-012-001, Clinical trial registration No. KCT 0002303).

\section{Endoscopic procedures}

\section{Endoscopic mucosal resection (EMR)}

We performed EMR with a single-channel endoscope (GIF-Q260, Olympus Medical Systems Corporation, Tokyo, Japan). A mixture of $0.9 \%$ saline solution, a small quantitiy of indigocarmine, and $0.001 \%$ diluted epinephrine was injected into the submucosal layer under the NET to reduce resection margin involvement and the risk of perforation. Then, the tumor was caught by the snare and resected using an Endocut $Q$ current (effect 2, cut duration 1, cut interval 4) which was generated by using a VIO300D electrosurgical unit (ERBE Elektromedizin $\mathrm{GmbH}$, Tübingen, Germany). The resectied tissue was retrieved by a grasping forcep (Olympus, Optical Co.).

\section{EMR using a band-ligation device (EBL)}

A single-channel endoscope (GIF-Q260, Olympus 
Medical Systems Corporation, Tokyo, Japan) with a band ligation device (MD-48710 EVL Device; Sumitomo Bakelite Co. Ltd, Tokyo, Japan) mounted on the tip was used. Similar to EMR, the solution described above was injected into the submucosal layer. Then, the tumor was drawn into a band-ligation before the elastic band was deployed.Snare resection was performed under the band in the same way as EMR (fig. 1). To prevent post-procedure bleeding and perforation, the lesion floor was sealed with clip after resection. The resected specimen was aspirated into the cap and then retrieved.

\section{Endoscopic submucosal dissection (ESD)}

ESD was carried out using previously mentioned endoscope. To obtain a steady endoscopic vision and to provide countertraction for submucosal dissection to the connective tissue, a transparent hood was mounted on to the tip of the endoscope. Similar to EBL and EMR, the solution described above was injected into the submucosal layer. After lifting the tumor, a Dual Knife (KD-650 L; Olympus Medical Systems Corporation, Tokyo, Japan) was used to incise the surrounding mucosa of NET. In order to create a sufficient lateral resection margin without a tumor, mucosal incisions were made at least 2 to $3 \mathrm{~mm}$ apart around the lesion.

After the mucosal incision, the submucosal tissue under the tumor was dissected step by step from the muscle layer. NET was completely isolated after sufficient submucosal dissection. All mucosal incisions and submucosal dissections were performed using an Endocut $Q$ current (effect 2, cut duration 3, cut interval 4) and a Swift coagulation current (effect 4, 40 W) generated by previously mentioned VIO300D electrosurgical unit. Hemostatic forceps (SDB2422; Pentax HOYA, Tokyo, Japan) were used to control visible
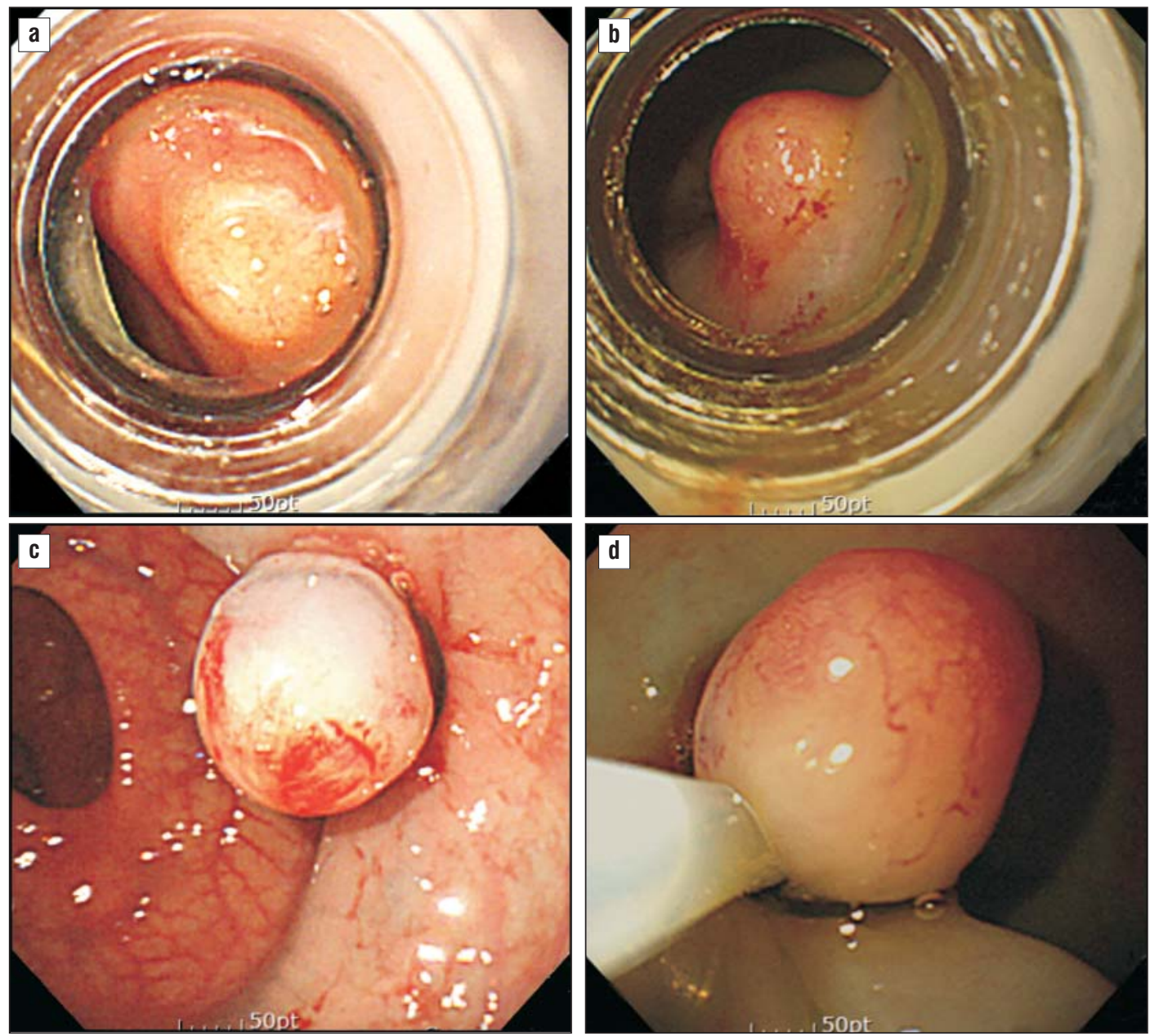

Figure 1 - Endoscopic submucosal resection with a ligation device

(a) A yellowish small NET was noted. (b) Submucosal saline solution is being injected beneath the NET

(c) An elastic band was deployed. (d) Snare resection is being carried out below the band. 

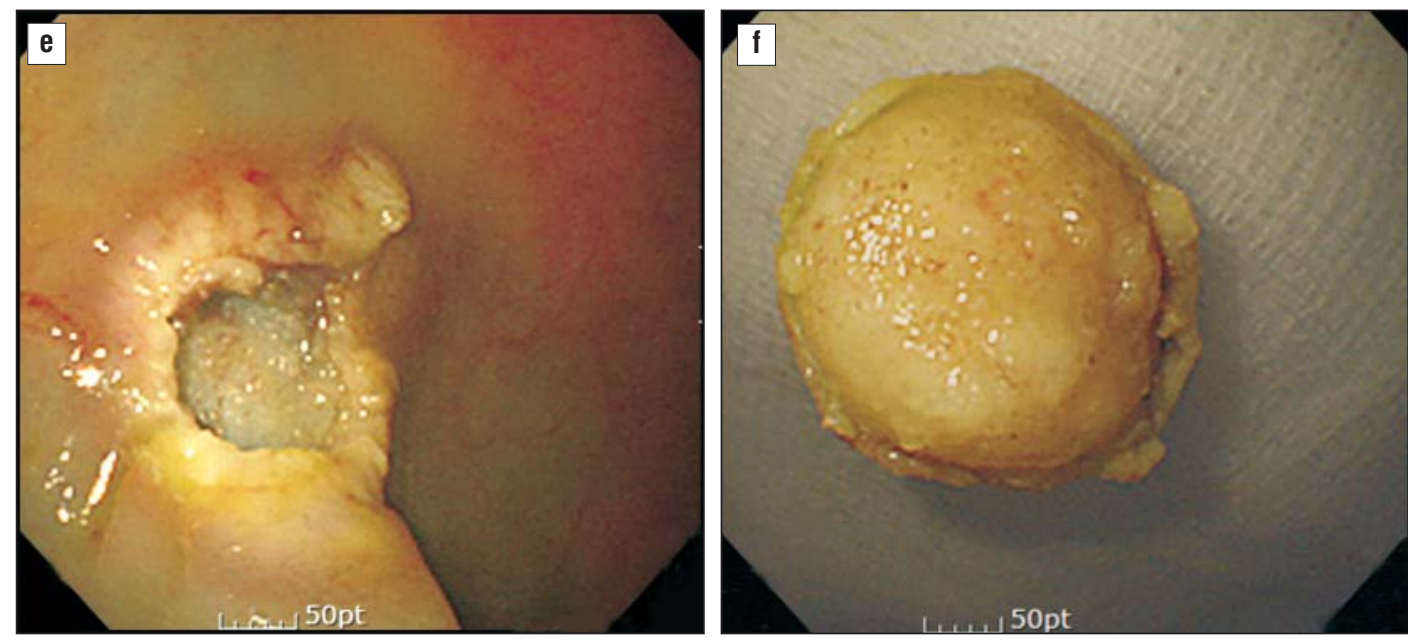

Figure 1 - Endoscopic submucosal resection with a ligation device

(e) Clear resection surface is observed.

(f) The resection specimen was retrieved.

(g) The resected floor was endospically closed with clips.

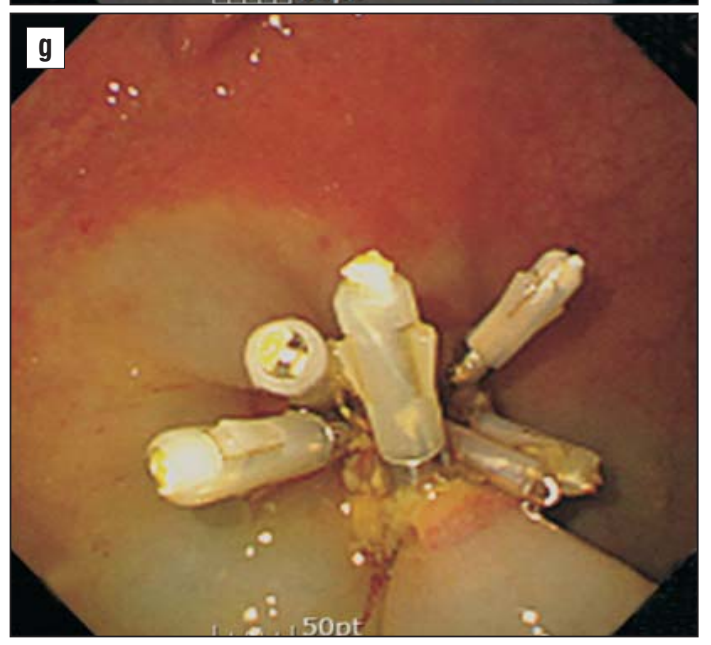

bleeding in soft coagulation mode (output 80W). After the NET was removed, endoscopic clipping for the lesion floor was performed in the same way as EBL. The resected specimen was retrieved by suction into the cap or by grasping with a net (Olympus, Optical Co.).

\section{Histopathologic evaluation}

The histologic size was assessed as the largest diameter in the freshly removed specimen. All resected samples were fixed in $10 \%$ formalin, cut into $2-\mathrm{mm}$ slices, and stained with hematoxylin-eosin. The depth of invasion, vertical and lateral resection margins, and lymphovascular invasion were determined by histologic examination. Histologic complete resection was defined as an en bloc resection without tumor involvement in the lateral and vertical margins of the resected sample and no invasion of the lymphovascular vessels. Resection margin involvement was defined as the presence of a microscopic tumor at the connected cutting edge or thermal distortion that interferes with the evaluation of this section.

\section{Data collection and assessment}

The data including histologic complete resection rate, procedure time, and procedure-related complications such as bleeding and perforations were assessed. The procedure time was defined as the time from the beginning of the submucosal injection until the completion of the tumor resection. Bleeding control time after resection was not included.

\section{Complications}

Post-procedure bleeding was defined as bleeding requiring hemostasis by endoscopy, radiologic intervention, or surgery, or bleeding with hemoglobin level dropping by $2 \mathrm{~g} / \mathrm{dL}$ (20). Post-procedure perforation was diagnosed if mesenteric fat or intraperitoneal space was directly observed during the procedure (frank perforation), or free air was detected in the simple chest X-ray after resection without obvious intestinal wall defect identified during the procedure (microperforation). 


\section{Follow-up evaluation}

All patients underwent sigmoidoscopy or colonoscopy, chest CT scan, abdominopelvic CT scan every 6 months for the first 3 years and then every year for 2 years to detect local recurrence, lymph node swelling and distant metastasis after endoscopic resection.

\section{Statistical analysis}

The Mann-Whitney or Kruskal-Wallis test was used as a continuous variable. Data analysis was performed using SPSS software (version 19.0; SPSS Inc., Chicago, IL, USA). All tests were 2-tailed and $P$ value less than 0.05 was considered statistically significant.

\section{RESULTS}

\section{Profiles of patients and tumors}

Of the 75 patients included in this study, 12 were treated with EBL, 43 were managed with EMR, and 20 underwent ESD. The baseline characteristics of patients and tumors are shown in table 1 . The mean age was similar among the EBL, the EMR, and ESD groups (48.1 years, 46.9 years, 50.9 years, respectively, $P=0.439$ ). The male to female ratio was also similar in the EBL, EMR, and ESD groups $(6: 6,25: 18,11: 9$, respectively, $P=0.878)$. Evidence of metastasis to lymph nodes or other organs was not found in the initial evaluation of the patient. The mean diameter of the tumors estimated by endoscopy was $8.42 \mathrm{~mm}$ in the EBL, $7.53 \mathrm{~mm}$ in the EMR, and 9.45 $\mathrm{mm}$ in the ESD group, respectively $(P=0.328)$. The mean pathologic tumor size in the three groups was similar (EBL: $5.20 \mathrm{~mm}$, EMR: $5.86 \mathrm{~mm}$, ESD: $8.90 \mathrm{~mm} ; P=0.440$ ). The mean tumor size assessed by endoscopy was larger than the mean tumor size based on pathologic evaluation.

Endoscopy showed that the tumor in the lower rectum was $25.0 \%$ in the EBL group, $53.5 \%$ in the EMR group, and $55.0 \%$ in the ESD group. All tumors showed elevated lesion with a smooth surface. No depressed lesions were observed. There was no difference in the tumor location or tumor size depending on each treatment group.

\section{Clinical results according to endoscopic treatment}

The clinical outcomes of the three groups are summarized in table 2. All tumors were resected in an en bloc fashion. Pathologically, the tumors were found in the submucosal layer in $100.0 \%$ of the EBL group, $97.7 \%$ in the EMR group, and $100.0 \%$ in the ESD group. Mitosis was observed $75.0 \%$ in the EBL group, $11.6 \%$ in the EMR group, and $10.0 \%$ in the ESD group. Lymphatic invasion was observed $0.0 \%$ in the EBL group, $4.7 \%$ in the EMR group, and $0.0 \%$ in the ESD group. Vascular invasion was not found in any group. Tumor-free lateral resection margin was observed $0.22 \mathrm{~mm}$ in the EBL group, $0.31 \mathrm{~mm}$ in the EMR group, and $1.56 \mathrm{~mm}$ in the ESD group. The tumor-free deep and lateral resection margins of EBL group were greater than in the EMR group $(P<0.001$ and $P=0.093$, respectively).

Involvement of the lateral resection margin was observed $8.3 \%$ in the EBL group, 2.3\% in the EMR group,

Table 1 - Baseline characteristics of the study groups

\begin{tabular}{|c|c|c|c|c|c|c|c|}
\hline Variable & $\begin{array}{l}\text { EBL group } \\
(n=12)\end{array}$ & $\begin{array}{l}\text { EMR group } \\
(\mathrm{n}=43)\end{array}$ & $\begin{array}{l}\text { ESD group } \\
(n=20)\end{array}$ & & & P-value & \\
\hline & & & & & 1 vs. 2 & 1 vs. 3 & 2 vs. 3 \\
\hline Age, years & $48.1 \pm 9.5$ & $46.9 \pm 10.7$ & $50.9 \pm 12.7$ & 0.439 & 0.582 & 0.585 & 0.214 \\
\hline Male, $n(\%)$ & $6(50)$ & $25(58.1)$ & $11(55.0)$ & 0.878 & 0.618 & 0.787 & 0.816 \\
\hline \multicolumn{8}{|l|}{ Tumor size } \\
\hline $\begin{array}{l}\text { Endoscopically } \\
\text { estimated } \\
\text { tumor size, mm }\end{array}$ & $8.42 \pm 3.08$ & $7.53 \pm 3.39$ & $9.45 \pm 4.97$ & 0.328 & 0.333 & 0.953 & 0.175 \\
\hline $\begin{array}{l}\text { Pathologic } \\
\text { tumor size, } \mathrm{mm}\end{array}$ & $5.20 \pm 2.61$ & $5.86 \pm 3.54$ & $8.90 \pm 7.16$ & 0.440 & 0.728 & 0.365 & 0.228 \\
\hline Tumor location & & & 0.187 & 0.083 & 0.103 & 0.911 & \\
\hline Upper rectum & $9(75.0)$ & $20(46.5)$ & $9(45.0)$ & & & & \\
\hline Lower rectum & $3(25.0)$ & 23 (53.5) & $11(55.0)$ & & & & \\
\hline
\end{tabular}

All results are presented as numbers (\%) or means \pm SDs. EBL: endoscopic submucosal resection with a ligation device; EMR: endoscopic mucosal resection; ESD: endoscopic submucosal dissection.

${ }^{a}$ Tumor location was defined as lower portion ( $\leq 7.5 \mathrm{~cm}$ from the anal verge) and lower portion (7.6-15 $\mathrm{cm}$ from the anal verge). 
Table 2 - Clinical outcomes according to endoscopic treatment modality

\begin{tabular}{|c|c|c|c|c|c|c|c|}
\hline \multirow[t]{2}{*}{ Variable } & \multirow{2}{*}{$\begin{array}{c}\text { EBL group } \\
(n=12)\end{array}$} & \multirow{2}{*}{$\begin{array}{c}\text { EMR group } \\
(\mathrm{n}=43)\end{array}$} & \multirow{2}{*}{$\begin{array}{l}\text { ESD group } \\
(n=20)\end{array}$} & & \multicolumn{3}{|c|}{ P-value } \\
\hline & & & & & 1 vs. 2 & 1 vs. 3 & 2 vs. 3 \\
\hline \multicolumn{8}{|l|}{ Pathologic results } \\
\hline Depth & & & & 0.689 & 0.597 & 1.000 & 0.495 \\
\hline Submucosa & $12(100.0)$ & $42(97.7)$ & $20(100.0)$ & & & & \\
\hline Mucosa & $0(0.0)$ & $1(2.3)$ & & & & & \\
\hline \multicolumn{8}{|l|}{0.828} \\
\hline & $0(3(25.0))$ & $0(38(88.4))$ & $0(18(90.0))$ & & & & \\
\hline & $1(7(58.4))$ & $1(4(9.3))$ & $1(2(10.0))$ & & & & \\
\hline & $2(1(8.3))$ & $4(1(2.3))$ & & & & & \\
\hline \multicolumn{8}{|c|}{$20(1(8.3))$} \\
\hline Lymphatic invasion & $0(0.0)$ & $2(4.7)$ & $0(0.0)$ & 0.470 & 0.451 & 1.000 & 0.331 \\
\hline Vascular invasion & $0(0.0)$ & $0(0.0)$ & $0(0.0)$ & 1.000 & 1.000 & 1.000 & 1.000 \\
\hline $\begin{array}{l}\text { Tumor-free lateral } \\
\text { resection margin, mm }\end{array}$ & $0.22 \pm 0.41$ & $0.31 \pm 0.64$ & $1.56 \pm 1.36$ & $<0.001$ & $<0.001$ & 0.003 & $<0.001$ \\
\hline $\begin{array}{l}\text { Tumor-free deep } \\
\text { resection margin, } \mathrm{mm}\end{array}$ & $0.19 \pm 0.42$ & $0.11 \pm 0.12$ & $0.30 \pm 0.17$ & 0.001 & 0.903 & 0.014 & $<0.001$ \\
\hline Lateral margin involvement & $1(8.3)$ & $1(2.3)$ & $3(15.0)$ & 0.170 & 0.330 & 0.587 & 0.057 \\
\hline Deep margin involvement & $4(33.3)$ & $10(23.3)$ & $3(15.0)$ & 0.487 & 0.483 & 0.232 & 0.455 \\
\hline Complete resection & $8(66.7)$ & $32(74.4)$ & $18(90.0)$ & 0.249 & 0.597 & 0.107 & 0.158 \\
\hline Salvage operation & $0(0.0)$ & $1(2.3)$ & $0(0.0)$ & 0.689 & 0.597 & 1.000 & 0.495 \\
\hline \multicolumn{8}{|l|}{ Complication } \\
\hline Perforation & $0(0.0)$ & $0(0.0)$ & $0(0.0)$ & 1.000 & 1.000 & 1.000 & 1.000 \\
\hline Bleeding & $3(25.0)$ & $0(0.0)$ & $0(0.0)$ & $<0.001$ & 0.001 & 0.021 & 1.000 \\
\hline Procedure time, $\min$ & $9.63 \pm 5.89$ & $3.90 \pm 1.21$ & $22.80 \pm 2.96$ & $<0.001$ & $<0.001$ & $<0.001$ & $<0.001$ \\
\hline Local recurrence during follow-up & $0(0.0)$ & $2(4.7)$ & $0(0.0)$ & 0.470 & 0.451 & 1.000 & 0.331 \\
\hline Distant metastasis during follow-up & $0(0.0)$ & $2(4.7)$ & $0(0.0)$ & 0.470 & 0.451 & 1.000 & 0.331 \\
\hline Follow-up period, month & $22.8 \pm 10.9$ & $56.3 \pm 33.5$ & $47.3 \pm 43.3$ & 0.005 & $<0.001$ & 0.436 & 0.237 \\
\hline
\end{tabular}

All results are presented as numbers (\%) or means \pm SDs. EBL: endoscopic submucosal resection with a ligation device; EMR: endoscopic mucosal resection; ESD: endoscopic submucosal dissection

and $15.0 \%$ in the ESD group $(P=0.170)$. The rate of lateral resection margin involvement was higher in the ESD group than in the EBL and EMR groups. Involvement of the deep resection margin was observed $33.3 \%$ in the EBL group, $23.3 \%$ in the EMR group, and $15.0 \%$ in the ESD group ( $P=0.487)$. The rate of deep resection margin involvement was lower in the ESD group than in the EBL and EMR groups.

The histologic complete resection rate was $[66.7 \%$; (8 of 12)] in the EBL group, [74.4\%; (32 of 43)] in the EMR group, and [90.0\%; (18 of 20)] in the ESD group $(P=0.249)$. Only one patient $(2.3 \%)$ who did not undergo endoscopic complete resection after EMR received additional surgery. The remaining patients who underwent histologically incomplete resection did not undergo additional surgery because they underwent endoscopic complete resection (R1 resection). No patient underwent additional surgical resection after EBL and ESD.

\section{Procedure times and procedure-related complications}

The procedure related bleeding occurred in the EBL group only (three cases (25.0\%)). All bleeding was controlled endoscopically using clips. There was no perforation in the all three groups. The mean procedure time was significantly longer in the ESD group than in the EBL and EMR groups (22.8 minutes vs. 9.6 and 3.9 minutes, $\mathrm{P}<0.001$ ). 


\section{Follow-up}

Endoscopy and CT scans demonstrated that there were two local recurrence in the EMR group [2 cases $(4.7 \%)]$ and two distant metastasis in the EMR group [2 cases $(4.7 \%)]$.

\section{DISCUSSION}

Rectal NETs are mostly detected at an early stage by active diagnostic endoscopy (1). Rectal NETs are mostly small, and $66 \%$ of NET are less than $10 \mathrm{~mm}$ in diameter (3). Risk factors for metastasis in rectal NET are more than $10 \mathrm{~mm}$ in diameter, muscle involvement, poorly differentiated neuroendocrine pathology, and lymphovascular invasion. The size of the tumor is considered to be the most important factor associated with metastasis of rectal NETs $(3,8,21)$. The metastatic potential for rectal NETs smaller than $10 \mathrm{~mm}$ is less than $2 \%(18,22)$.

Endoscopic resection is widely accepted as a curative treatment method of rectal NET smaller than $10 \mathrm{~mm}$. However, there is still a debate over what the best endoscopic treatment is to easily and effectively remove the rectal NET. Conventional EMR is a widely used simple method to treat small rectal NET. However, most rectal NETs extend to the submucosal layer, so that conventional EMR can not remove the tumor with sufficient vertical resection margins in many cases, even if the tumor is less than $10 \mathrm{~mm}$ in diameter $(7,8,23,24)$. In the case of incomplete resection of the tumor, additional endoscopic resection of the residual tumor is difficult due to fibrosis that prevents the lesion from being lifted by submucosal injection after initial incomplete endoscopic resection (25). Therefore, complete resection is technically very important in rectal NET treatment strategies.

ESD technique is superior to conventional EMR in terms of higher en bloc and pathologically complete resection in rectal NET therapy. However, ESD is technically complex and difficult, time-consuming, with a significant risk of perforation or bleeding, and is not yet widely accepted in the treatment of colorectal neoplasms $(26,27)$. The ESD perforation rate for colorectal neoplasms was much higher than the ESD perforation rate for stomach tumors, so the safety profile related to ESD was not established for colorectal neoplasms $(13,14,28)$.

Endoscopic mucosal resection using band ligation (EBL) is proposed as another feasible novel effectiv treatment for rectal NET to overcome the shortcomings of conventional EMR $(9,17)$. EBL can achieve a higher curative resection rate for NET than conventional EMR by allowing the entire tumor and adjacent submucosal tissue to be aspirated into a capto remove significantly deeper vertical portions of the submucosal layer below the tumor $(9,16,17,29)$. Compared to $\operatorname{ESD}, \operatorname{EBL}$ is technically easy and has significantly shorter processing times.

This study shows that EBL is as effective as ESD for rectal NET smaller than $10 \mathrm{~mm}$ in complete histologic resection rate $(66.7 \%$ vs. $90.0 \%, p=0.107)$. The tumorfree lateral and deep resection margins of EBL group were larger than those of the EMR group $(P<0.001$ and $P=0.093$, respectively). Lymphovascular invasion in rectal NET is known to be associated with poor prognosis and an elevated mitotic rate (30). In this study, invasion of lymphatic vessels occurred only in the EMR group (4.7\%). If endoscopists are not experts for colorectal ESD, many complications can occur $(12,14)$. There was no perforation in this study. In this study, the procedure time of ESD was significantly longer than EBL (22.80 vs. 9.63 min; $P<0.001)$. EBL, a modified EMR technique, is very easy and simple for endoscopists who have colorectal EMR experience and is a time-saving method compared to ESD. Until now, no lymph node,local, or distant metastases have been found in the EBL or ESD group. During the follow-up period, two local recurrence and two distant metastasis were found in the EMR group. With respect to local recurrence and distant metastasis, EBL is superior to conventional EMR and comparable with ESD.

The advantage of this study is that relatively large numbers of patients with rectal NETs $15 \mathrm{~mm}$ in diameter or less were consecutively enrolled. Another strength of this study was a relatively long follow-up period.

The limitation of present study is that this study was not a randomized prospective control study and procedures were performed according to the preference of each endoscopist.

\section{CONCLUSIONS}

Compared with EMR, EBL showed similar procedure time, similar complication rate, lower recurrence rate, less lymphatic invasion, and deeper tumor free resection margin. EBL enables a deep vertical resection margin and a high complete resection rate comparable to ESD. In addition, EBL is technically easy to perform and can be safely performed in less time than ESD.Considering the benefits of ease, efficiency, and short procedure time, EBL could be considered either an alternative to ESD or an optional therapy for small rectal NET. 


\section{Conflicts of interest}

The authors state that there is no interest in the manuscript, including financial, consultants, institutions and other relationships that could lead to prejudice or conflicts of interest.

\section{REFERENCES}

1. Modlin IM, Sandor A. An analysis of 8305 cases of carcinoid tumors Cancer. 1997;79(4):813-29.

2. Teleky B, Herbst F, Längle F, Neuhold N, Niederle B. The prognosis of rectal carcinoid tumours. Int J Colorectal Dis. 1992;7(1):11-4.

3. Soga J. Carcinoids of the rectum: an evaluation of 1271 reported cases. Surg Today. 1997;27(2):112-9.

4. Modlin IM, Lye KD, Kidd M. A 5-decade analysis of 13,715 carcinoid tumors. Cancer. 2003:97(4):934-59.

5. Fahy BN, Tang LH, Klimstra D, Wong WD, Guillem JG, Paty PB, et al. Carcinoid of the rectum risk stratification (CaRRs): a strategy for preoperative outcome assessment. Ann Surg Oncol. 2007;14(5): 1735-43. Epub 2007 Feb 9.

6. Koura AN, Giacco GG, Curley SA, Skibber JM, Feig BW, Ellis LM. Carcinoid tumors of the rectum: effect of size, histopathology, and surgical treatment on metastasis free survival. Cancer. 1997; 79(7):1294-8.

7. Baek IH. Endoscopic submucosal dissection or conventional endoscopic mucosal resection is an effective and safe treatment for rectal carcinoid tumors: a retrospective study. J Laparoendosc Adv Surg Tech A. 2010;20(4):329-31. doi: 10.1089/lap.2009.0373.

8. Park CH, Cheon JH, Kim JO, Shin JE, Jang BI, Shin SJ, et al. Criteria for decision making after endoscopic resection of well-differentiated rectal carcinoids with regard to potential lymphatic spread. Endoscopy. 2011;43(9):790-5. doi: 10.1055/s-0030-1256414. Epub 2011 Jul 6.

9. Ono A, Fujii T, Saito Y, Matsuda T, Lee DT, Gotoda T, et al. Endoscopic submucosal resection of rectal carcinoid tumors with a ligation device. Gastrointest Endosc. 2003;57(4):583-7.

10. Nagai T, Torishima R, Nakashima $\mathrm{H}$, Ookawara $\mathrm{H}$, Uchida A, Kai S, et al. Saline-assisted endoscopic resection of rectal carcinoids: cap aspiration method versus simple snare resection. Endoscopy. 2004; 36(3):202-5.

11. Oshitani N, Hamasaki N, Sawa Y, Hara J, Nakamura S, Matsumoto T, et al. Endoscopic resection of small rectal carcinoid tumours using an aspiration method with a transparent overcap. J Int Med Res. 2000;28(5):241-6

12. Tanaka S, Oka S, Kaneko I, Hirata M, Mouri R, Kanao H, et al. Endoscopic submucosal dissection for colorectal neoplasia: possibility of standardization. Gastrointest Endosc. 2007;66(1):100-7.

13. Saito Y, Uraoka T, Matsuda T, Emura F, Ikehara H, Mashimo Y, et al. Endoscopic treatment of large superficial colorectal tumors: a case series of 200 endoscopic submucosal dissections (with video) Gastrointest Endosc. 2007; 66(5):966-73. Epub 2007 May 24.

14. Fujishiro M, Yahagi N, Kakushima N, Kodashima S, Muraki Y, Ono S, et al. Outcomes of endoscopic submucosal dissection for colorectal epithelial neoplasms in 200 consecutive cases. Clin Gastroenterol Hepatol. 2007;5(6):678-83; quiz 645. Epub 2007 Apr 26.
15. Park HW, Byeon JS, Park YS, Yang DH, Yoon SM, Kim KJ, et al. Endoscopic submucosal dissection for treatment of rectal carcinoid tumors. Gastrointest Endosc. 2010;72(1):143-9. doi: 10.1016/ j.gie.2010.01.040. Epub 2010 Apr 9.

16. Abe T, Kakemura T, Fujinuma S, Maetani I. Successful outcomes of EMR-L with 3D-EUS for rectal carcinoids compared with historical controls. World J Gastroenterol. 2008;14(25):4054-8.

17. Mashimo $Y$, Matsuda T, Uraoka T, Saito $Y$, Sano $Y$, Fu K, et al. Endoscopic submucosal resection with a ligation device is an effective and safe treatment for carcinoid tumors in the lower rectum. J Gastroenterol Hepatol. 2008;23(2):218-21. doi: 10.1111/ j.1440-1746.2008.05313.x.

18. Kwaan MR1, Goldberg JE, Bleday R. Rectal carcinoid tumors: review of results after endoscopic and surgical therapy. Arch Surg. 2008; 143(5):471-5. doi: 10.1001/archsurg.143.5.471.

19. Saitoh Y, Iwashita A, lida M. A questionnaire surveyconcerning colorectal carcinoid tumors-therapeutic strategyfor colorectal carcinoid tumors. Stomach \&Intestine. 2005;40:200-213.

20. Higashiyama M, Oka S, Tanaka S, Sanomura Y, Imagawa H,Shishido $T$, et al. Risk factors for bleeding after endoscopic submucosal dissection of gastric epithelial neoplasm. Dig Endosc. 2011;23(4): 290-5. doi: 10.1111/j.1443-1661.2011.01151.x. Epub 2011 May 10.

21. Jetmore AB, Ray JE, Gathright Jr JB, McMullen KM, Hicks TC, Timmcke AE. Rectal carcinoids: the most frequent carcinoid tumor. Dis Colon Rectum. 1992;35(8):717-25.

22. Modlin IM, Oberg K, Chung DC, Jensen RT, de Herder WW,Thakker RV, et al. Gastroenteropancreatic neuroendocrine tumours. Lancet Oncol. 2008;9(1):61-72. doi: 10.1016/\$1470-2045(07)70410-2.

23. Matsui K, Iwase T, Kitagawa M. Small, polypoid-appearing carcinoid tumors of the rectum: clinicopathologic study of 16 cases and effectiveness of endoscopic treatment. Am J Gastroenterol. 1993; 88(11): 1949-53.

24. lishi $\mathrm{H}$, Tatsuta $\mathrm{M}$, Yano $\mathrm{H}$, Narahara $\mathrm{H}$, Iseki $\mathrm{K}$, Ishiguro $\mathrm{S}$. More effective endoscopic resection with a two-channel colonoscope for carcinoid tumors of the rectum. Dis Colon Rectum. 1996;39(12): $1438-9$

25. Han KS, Sohn DK, Choi DH, Hong CW, Chang HJ, Lim SB, et al. Prolongation of the period between biopsy and EMR can influence the nonlifting sign in endoscopically resectable colorectal cancers. Gastrointest Endosc. 2008;67(1):97-102.

26. Baek IH, Jeon JW, Shin HP, Cha JM, Joo KR, Lee Jl, et al. Successful en bloc resection of an esophageal hemangioma by combined EBL \& EMR: a case report and technical review. TransI Gastroenterol Hepatol. 2016;1:45. doi: 10.21037/tgh.2016.05.07. eCollection 2016.

27. Kim JH, Baek IH, Kim KO, Jang HJ, Baik GH, Lee CK, et al. Usefulness and feasibility of endoscopic submucosal dissection for colorectal tumor: a nationwide multicenter retrospective study in Korea. J Gastrointest Oncol. 2016;7(6):924-930. doi: 10.21037/ jgo.2016.06.08.

28. Fujishiro M, Yahagi N, Nakamura M, Kakushima N, Kodashima S, Ono S, et al. Endoscopic submucosal dissection for rectal epithelial neoplasia. Endoscopy. 2006;38(5): 493-7.

29. Berkelhammer C, Jasper I, Kirvaitis E, Schreiber S, Hamilton J, Walloch J. et al. "Band-snare" resection of small rectal carcinoid tumors. Gastrointest Endosc. 1999:50(4):582-5.

30. Fahy BN, Tang LH, Klimstra D, Wong WD, Guillem JG, Paty PB, et al. Carcinoid of the rectum risk stratification (CaRRs): a strategy for preoperative outcome assessment. Ann Surg Oncol. 2007;14(5): 1735-43. Epub 2007 Feb 9 